\title{
РИСКИ ПОТЕРИ УСТОЙЧИВОСТИ В ИНВЕСТИЦИОННОЙ ДЕЯТЕЛЬНОСТИ БАНКОВ
}

\section{RISKS OF LOSS OF STABILITY IN THE INVESTMENT ACTIVITIES OF BANKS}

\section{T. Fedorenko}

Summary. For dynamically developing commercial organizations, investment is one of the most important aspects of their activities. The presence of a direct relationship between the efficiency of the bank and the level of investment risks requires the development of methods for their rational management. However, at present, risk management activities in investment activities in most cases are reduced mainly to qualitative analysis and assessment of variations in the main indicators of investment activities with a minimum number of risk-forming factors. However, the number of risk factors caused by changes in the external and internal environment, as well as the uncertainty of their impact on investment activity, do not allow us to speak of the existence of a truly effective risk management mechanism, supported by practical mechanisms. minimize risks.

Keywords: investment activities, risks, financial stability, commercial organizations, risk management, risk analysis, banks. и нвестиционная деятельность банка существенна как для него самого, поскольку является его основным источником дохода, так и для экономики страны в целом, необходимо давать оценку такой деятельности. Эти действия должны минимизировать существующие риски и улучшить состояние кредитного и инвестиционного портфеля банка.

Актуальность темы изучения рисков потери устойчивости инвестиционной деятельности банков связана с нестабильным состоянием международных финансовых рынков, неполнотой исследований в этой области, открывающимися возможностями использования методов оценки этих рисков.

В частности, актуальность управления финансовыми рисками на международных рынках связана с тем, что риски увеличиваются, произошла их глобализация, ценовые спрэды сузились, а волатильность валют, процентных ставок, цен на ценные бумаги и сырьевых товаров увеличилась. В целом финансовые рынки стали более нестабильными, сложными и рискованными.
Федоренко Татьяна Сергеевна

Аспирант, Российский экономический университет

им. Г.В. Плеханова

ymka-0795@bk.ru

Аннотация. Для динамично развивающихся коммерческих организаций инвестиции - один из важнейших аспектов их деятельности. Наличие прямой зависимости между эффективностью деятельности банка и уровнем инвестиционных рисков требует разработки методов их рационального управления. Однако в настоящее время деятельность по управлению рисками в инвестиционной деятельности в большинстве случаев сводится В основном к качественному анализу и оценке вариаций основных показателей инвестиционной деятельности с минимальным количеством рискообразующих факторов. Однако количество факторов риска, вызванных изменениями внешней и внутренней среды, а также неопределенность их влияния на инвестиционную деятельность не позволяют говорить о существовании действительно эффективного механизма управления рисками, подкрепленного практическими механизмами. минимизировать риски.

Ключевые слова: инвестиционная деятельность, риски, финансовая устойчивость, коммерческие организации, управление рисками, анализ рисков, банки.

Банковское инвестирование представляет собой деятельность банка, по размещению финансовых ресурсов, осуществление инвестиций на определенный период времени для получения прибыли, социального эффекта или других целей.

Банковская организация как инвестиционный посредник аккумулирует крупные капиталы временно свободных денежных средств и вкладов населения с помощью различных денежных и финансовых инструментов привлечения средств. Все это свидетельствует о большом инвестиционном спросе банковского учреждения на денежные ресурсы, а формирование крупных денежных средств является обязательным условием формирования инвестиционного потенциала банка и банковской системы в целом.

Инвестиционная деятельность банка важна как для экономики страны в целом, так и для самого банковского учреждения. Для экономики страны важность инвестиционной деятельности банка заключается в том, что банк, аккумулируя финансовые ресурсы физических 
и юридических лиц, направляет средства на наиболее привлекательные инвестиционные проекты, стимулируя развитие реального сектора и социальной сферы; обеспечивает формирование финансовых возможностей для повышения благосостояния страны в целом.

Управление банковскими инвестициями включает в себя:

1. установление оптимальной пространственной и временной структуры, а также объемов банковских инвестиций;

2. повышение эффективности банковской инвестиционной деятельности с целью уменьшения расходов и получения высоких результатов;

3. разработку новых банковских инвестиционных продуктов, которые повысят спрос и обеспечат банку максимальную прибыль;

4. подбор высококвалифицированного персонала для банковско-инвестиционной деятельности и ее эффективное использования [5].

Риск - это вероятность неблагоприятного исхода. Инвестиционный риск может быть представлен как вероятность потери инвестиций, неполучения от них полной отдачи и обесценивания инвестиций. Различные инвестиционные проекты имеют разную степень риска. Как правило, самый выгодный вариант капитальных вложений также и самый рискованный. Риски в инвестиционной деятельности банка связаны со следующими факторами:

- полной или частичной невыплатой ожидаемого дохода по вложенным средствам;

- обесценении помещенных в ценные бумаги средств при росте инфляции;

- задержки в получении дохода;

- появлении проблем с переоформлением права собственности на приобретенные ценные бумаги.

Сегодня диверсификация портфеля ценных бумаг один из наиболее широко используемых банками методов снижения рисков. Для минимизации инвестиционных рисков необходимо обеспечить в портфеле от 10 до 15 различных ценных бумаг. При этом следует учитывать, что чрезмерная диверсификация может привести к трудностям в качественном управлении портфелем. Эти трудности связаны с ростом затрат, покупкой недостаточно надежных, прибыльных и высоколиквидных ценных бумаг, с поиском ценных бумаг, высокими затратами на покупку небольших пакетов и другими факторами.

Также инвестиционные риски возникают при проектном кредитовании, к примеру, программы для малого и среднего бизнеса.
Во избежание риска используют следующие методы:

1. Анализ рынка, в который хочет выйти клиент;

2. Анализ бизнес-плана кредитуемой организации;

3. Анализ потенциальных конкурентов [3].

В их основе лежит специфика организации распределения финансовых рисков. В американской модели риски в максимальной степени разделены на коммерческие и инвестиционные и диверсифицированы посредством ряда уровней страхования: система финансирования предприятий через выпуск ценных бумаг и механизм фондового рынка, кредитование специализированных инвестиционных банковских и небанковских институтов. В германской модели контроль рисков обеспечивается универсальными коммерческими банками, являющимися одновременно основными кредиторами реального сектора и главными субъектами финансового рынка.

Отечественные ученые сделали значительный шаг вперед в направлении исследования банковских рисков и формирования системы управления рисками для поддержания финансовой устойчивости банков. Когда дело доходит до «системы управления рисками», они предполагают систему процессов принятия управленческих решений, которая сводит к минимуму неопределенность в принятии решений. Регулирующие органы также оказывают поддержку формированию и развитию систем управления рисками в банках. Центральный банк подчеркивает необходимость создания каждым банком собственной системы управления рисками. Центральный банк выделяет следующие основные функции этих систем: идентификация (идентификация рисков), контроль, мониторинг, измерение рисков [4].

Эффективность управления инвестиционным риском напрямую влияет на уровень финансовой устойчивости коммерческого банка. В частности, способность банка регулировать риски, нейтрализовать их негативное влияние положительно влияет на основные факторы финансовой устойчивости, в противном случае есть предпосылки для дестабилизации финансового состояния банка. К числу рисков, которые больше всего влияют на основные характеристики финансовой устойчивости коммерческого банка, относятся кредитный, процентный риск и риск ликвидности.

Понятно, что большое значение имеют в первую очередь такие риски, как операционный, валютный, рыночный. Кроме того, на кредитный, процентный и риск ликвидности большое внимание обращают органы надзора, и коммерческие банки считают такие риски опасными для своего финансового положения. Однако, на финансовую устойчивость коммерческих организаций оказывают влияние все виды рисков, в том числе и инвестиционные риски. Не изученность данных рисков, понижает 


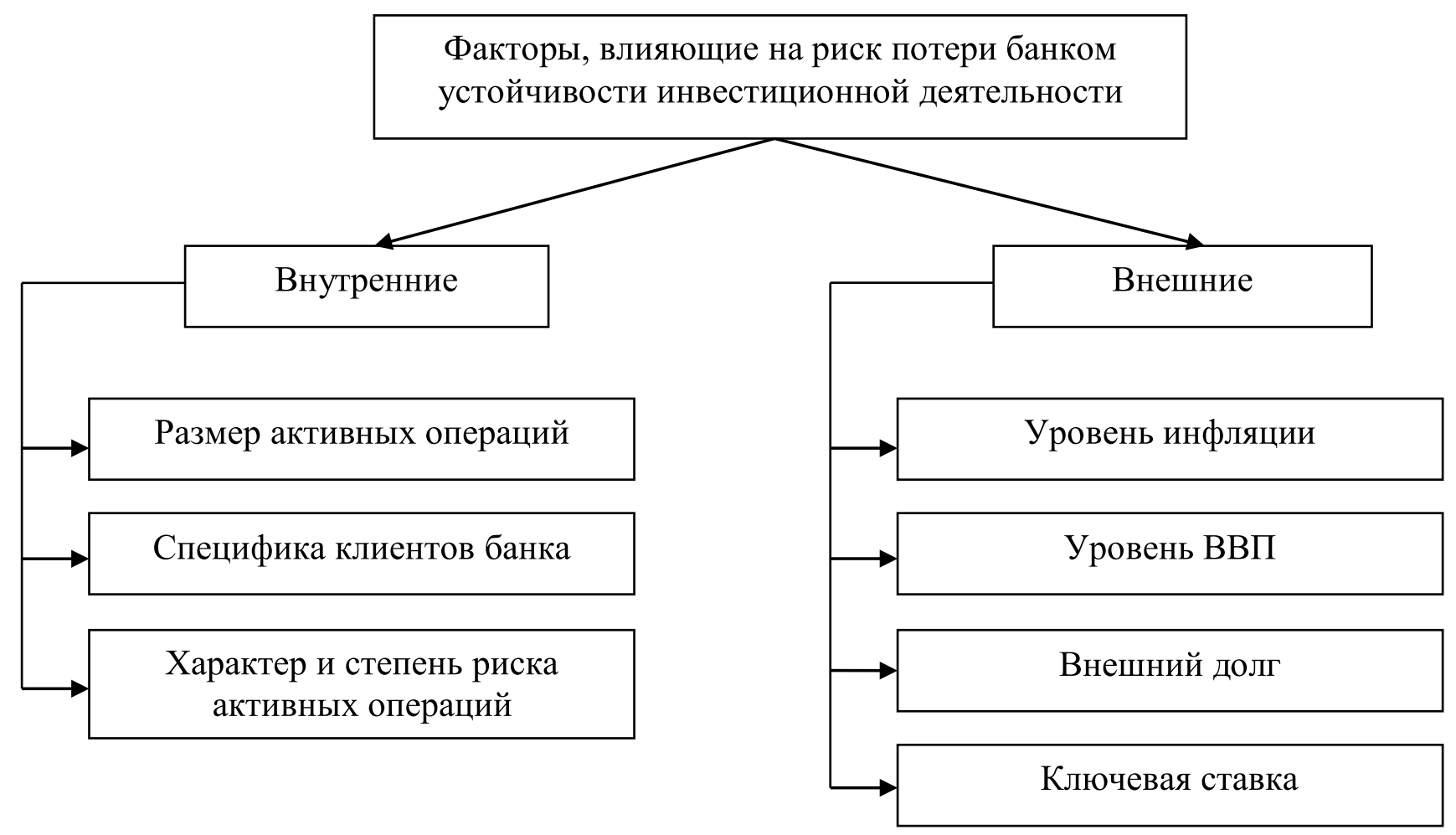

Рис. 1. Факторы, влияющие на риск потери банком устойчивости инвестиционной деятельности [2]

финансовую устойчивость всех банков, занимающихся инвестиционной деятельностью.

Перейдем к определению факторов, которые могут влиять на риск потери банком устойчивости инвестиционной деятельности. Их можно разделить на две группы факторов: внешние и внутренние (рисунок 1).

К внутренним факторам относятся:

- Размер активных операций предполагает, что что банки должны иметь собственный капитал в таком объеме, чтобы иметь возможность удовлетворять потребности своих постоянных клиентов в заемных средствах, не нарушая установленных стандартов.

- Специфика клиентов банка говорит о том, что преобладание клиентов, представленных крупными предприятиями, требует от банка большего размера собственного капитала и создает большие риски для банка на одного заемщика по сравнению с другими банками, которые ориентируются на мелких клиентов с таким же объемом активных операций.

- Характер и степень риска активных операциий - преобладание ссуд с минимальным риском в ссудном портфеле банка приводит к относительному уменьшению объема собственного капитала банка, и, наоборот, ориентация банка на совершение операций со значительным риском с использованием новейших технологий требует от банка наличия большего количество собственных средств [1].

Однако внутренние факторы невозможно проанализировать по всей банковской системе, так как они зависят от особенностей деятельности каждого отдельного банка, а именно от направления деятельности, цели кредитной и депозитной политики банка, качества финансового и организационного менеджмента, маркетинга банка.

К внешним факторам относятся:

- Уровень инфляциии показывает, как изменились цены в экономике, и измеряется с помощью индексов цен (индекса потребительских цен, дефлятора ВВП и т.п.) как разница между значением этого индекса за определенный период (в процентах) и $100 \%$;

- Уровень ВВП показывает уровень развития отечественной экономической системы;

- Внешний долг, который характеризует долговые обязательства государства перед нерезидентами по возврату заемных средств (основная сумма долга) и процентов по ним;

- Ключевая ставка, которая показывает направление денежно-кредитной политики [1]. 
Банки со значительными инвестиционными потерями подвержены риску снижения своей стоимости. На финансовом рынке Российской Федерации инвестиционный рынок является доминирующим по сравнению, например, с фондовым рынком, поэтому кредитный риск опасен для банков. Этот риск может значительно снизить прибыль банка, а в худшем случае привести к банкротству. Так, ненадлежащее управление кредитным риском влечет возникновение неработающих активов, убытков по кредитам, что значительно снижает уровень доходности, уменьшает стоимость банка и в конечном итоге негативно отражается на финансовой устойчивости в целом. Соответственно, специалисты банковского рынка, ведущие банкиры понимают необходимость эффективной организации управления рисками, одни крупные банки внедрили, другие стремятся внедрить соответствующую организационную структуру управления рисками. Если говорить о небольших банках, то в большинстве из них нет отдела риск-менеджмента, а иногда даже нет ни одного специалиста в банке с соответствующей функциональной нагрузкой.

Следует заметить, что необходимость банка учитывать объемы и специфику своей деятельности в процессе формирования системы управления рисками потери финансовой устойчивости является вполне оправданной, поскольку внедрение и функционирование системы риск-менеджмента требует немалых затрат (построение технологии управления рисками; подбор, покупка и вне- дрение программного обеспечения, поддержка технологии на актуальном уровне), что при нерациональном подходе, разумеется, негативно сказывается на уровне банковской доходности.

Чтобы минимизировать влияние банковских рисков на финансовую устойчивость, необходимо обеспечить комплексное управление, которое должно осуществляться системой управления рисками. Для государственных органов и Центрального банка основными направлениями обеспечения развития и улучшения функционирования системы управления рисками потери финансовой устойчивости банков являются: совершенствование нормативной базы регулирования банковских рисков; увеличение доли фондового рынка и развитие кредитных бюро, рейтинговых агентств; поощрение банков к внедрению комплексных систем управления рисками, особенно в банках с крупными активами.

Для коммерческих банков основными направлениями обеспечения развития и совершенствования системы управления рисками являются: обеспечение функционирования единого отдела управления рисками, его структурная и финансовая независимость от подразделений банка (фронт-офисы и бэк-офисы), а также а также формирование оптимальной организационной структуры, которая бы органично охватывала управление рисками на всех этапах банковской деятельности.

\section{ЛИТЕРАТУРА}

1. Балабанов А.И. Банки и банковское дело: учебное пособие.— СПб: Питер, 2013.— C 98-100.

2. Звонова Е.А. Деньги, кредит, банки: учебное пособие.—М.: Инфра-М, 2018. - С. 140.

3. Магзумова Н.В. Управление рисками в коммерческих банках // Научный вестник Южного института менеджмента. — 2018. — № 3. — С. 68.

4. Симоненко Н.Н. Управление рисками в коммерческих банках // Международный журнал экспериментального образования.—2015.— № 11. — С. 557.

5. Тарасенко 0.А. Предпринимательская деятельность субъектов банковской системы России: монография.— М.: Проспект. 2015. — 123-133 с. 